\title{
Orthodontic Smile: A New Categorization of the Perfect Smile
}

\author{
Maria do Rosário Dias, Ana Ferreira, Maria Calejo Pires, Valter Alves, Ana Delgado \\ Centro de Investigação Multidisciplinar em Psicologia da Saúde, Egas Moniz - Cooperativa de Ensino Superior, Almada, Portugal
}

\section{Abstract}

Background and Aim: There is a shortage of empirical studies that combine the problem of malocclusion to the importance of the self-perception of the mouth/smile in the mental representation of the self-image of the face, which is the aim of the present qualitative and exploratory study. Subjects and Methods: The convenience sample consisted of 151 children and youngsters of both genders, aged 8-24 years, who used an orthodontic appliance for 6 months to 1 year, and were invited to draw two portraits of their mouth/smile before (M1) and after (M2) the use of an orthodontic appliance. Results: The main reasons that underpin the use of an orthodontic appliance are defined by the crooked teeth correction, malocclusion correction, and interdental spaces categories, in which having the perfect smile was only relevant to preteens. Discussion and Conclusions: In the present study, we have identified the orthodontic smile as a new categorization of a perfect smile associated with the social display of a look with perfect teeth.

Keywords: Aesthetic smile, mental representation, orthodontic smile, self-image of the face

\section{INTRODUCTION}

Understanding the importance of a smile in the daily life of individuals remains a subject of high scientific interest. ${ }^{[1]}$ In a clinical context, the "art of the smile" resides in the Dentist's ability to recognize the positive beauty elements in each patient and to create a strategy that enhances the attributes that fall outside the parameters of the prevailing esthetic concept. ${ }^{[2]}$ In that sense, several authors have made contributions to the classifications of the smile.

According to Freitas-Magalhães, ${ }^{[3]}$ the smile is considered as a basic cognitive-affective competence and a feature in the development of one's personality, from birth until the end of the life trajectory. Freitas-Magalhães (2009) has defined four smile typologies: (i) the wide smile, (ii) the neutral smile, (iii) the superior smile, and (iv) the closed smile. Within this empirical perspective, the superior smile and the closed smile seem to be most connected to inter-psychosocial relations. Contrary, the wide smile and the neutral smile are not considered as affectionate, as they are on opposite extremes; while the wide smile displays the dental arch in its upper and lower jaws, the neutral smile displays no facial expressions. In addition, Sarver ${ }^{[4]}$ classified the smile arc as a type of smile defined by the "relationship of the curvature of the incisal edges of the maxillary incisors and canines to the curvature of the lower

\begin{tabular}{|l|l|}
\hline \multicolumn{2}{|c|}{ Access this article online } \\
\hline Quick Response Code: & Website: \\
& www.ejgd.org \\
\hline
\end{tabular}

lip in the posed smile" (p. 98), which seems to be equivalent to the superior smile in Freitas-Magalhães. ${ }^{[3]}$ According to Sarver, ${ }^{[4]}$ an ideal smile arc "has the maxillary incisal edge curvature parallel to the curvature of the lower lip" (p. 98), while in nonconsonant smile, "the smile arc is characterized by maxillary incisal arc line that is flatter than curvature of lower lip on smile" (p. 99). Sabri ${ }^{[5]}$ argued that the ideal smile was characterized by the balance between eight components that should not be considered as strict limits, but as artistic guidelines to help Orthodontists treat individual patients. Similar definitions of the ideal and nonconcordant smiles are proposed by additional authors. ${ }^{[2,4,6-9]}$ Moreover, Goldstein (2009) ${ }^{[10]}$ has differentiated the smile according to age, describing an older-appearing smile when the upper incisal edge appears straight during the smile and a younger-appearing smile when the central incisors are longer than the lateral incisors creating a greater interincisal distance.

Address for correspondence: Dr. Maria do Rosário Dias, Campus Universitário, Quinta da Granja, Monte de Caparica, 2829-511, Caparica, Portugal. E-mail: mrosariodias@egasmoniz.edu.pt

This is an open access journal, and articles are distributed under the terms of the Creative Commons Attribution-NonCommercial-ShareAlike 4.0 License, which allows others to remix, tweak, and build upon the work non-commercially, as long as appropriate credit is given and the new creations are licensed under the identical terms.

For reprints contact: reprints@medknow.com

How to cite this article: Dias Md, Ferreira A, Pires MC, Alves V, Delgado A. Orthodontic smile: A new categorization of the perfect smile. Eur J Gen Dent 2020;9:129-33.

Submitted: 08-May-2020 Accepted: 22-Jun-2020 Published: $15-$ Sep-2020 
In fact, the esthetic determination and attractiveness of the smile are very important in the orthodontic field, as they seem to play a more relevant and determining motivational treatment role than functional factors. ${ }^{[11,12]}$ Nonetheless, according to an empirical study conducted at the Egas Moniz-Lisbon University Clinic by Do Rosário Dias et al. ${ }^{[1]}$ the functional factor for orthodontic treatment motivation was greater than the aesthetic factor. Still, there is a shortage of empirical studies that combine the problem of malocclusion to the patient's esthetic perception of the face ${ }^{[13]}$ having into consideration the patient's psychosocial context. In fact, the orthodontic treatment leads to notorious changes in the patient's intrapsychic experience. The present study addresses this gap in knowledge, aimed at understanding the importance of the self-perception of the mouth and smile in the mental representation of the self-image of the face and in the well-being of the individual. In addition, this study has contributed to the definition of the orthodontic smile as an innovative classification associated with the perfect, well-functioning smile.

\section{Subjects and Methods}

An empirical study of descriptive and exploratory nature was carried out to access the self-perception of the mouth/smile in the mental representation of the individual. The methodological strategy was of the qualitative kind, through the content analysis of a collection of drawings made by patients, combined with quantitative parameters. Following the methodology of a research project realized by Do Rosário Dias et al., ${ }^{[1]}$ the convenience sample consisted of 151 children and youngsters of both genders, ages 8-24 years, who used an orthodontic appliance for 6 months $(6 \mathrm{M})$ to 1 year $(1 \mathrm{Y})$ and who were treated at the (Egas Moniz University Clinic Portugal (1)). Patients were invited to produce two self-portraits of their mouth/smile based on the following questions: (1)" What was your mouth like before you had the orthodontic appliance?" (Moment 1-[M1]); and (2) "How do you think your mouth will be when you remove the orthodontic appliance?" (Moment 2-[M2]). In addition, all participants answered a socio-demographic inquiry and provided a written answer to the question: "Why do you use an orthodontic appliance?" According to the selected sample, 302 valid drawings were collected and analyzed, half representing M1 ("What was your mouth like before you had the orthodontic appliance?") and half representing M2 ("How do you think your mouth will look like when you remove the orthodontic appliance?"). A qualitative content grid for the analysis of the 302 drawings was originally designed to study the pictorial representations found in the sample, with four categories: (1) "smile," (2) "drawing of the figure," (3) "appearance," and (4) "teeth." To further detail the content analysis, ten subcategories were created: (1) "absence of teeth," (2) "teeth without detail," (3) "fractured teeth," (4) "teeth with diastema," (5) "crowded teeth," (6) "crooked teeth," (7) "teeth in saw," (8) "misplaced teeth," (9) "teeth with spacing" and (10) "gingival deformation [Table 1].

The use of drawings as a pictorial instrument for research purposes of qualitative nature has been observed as a methodological guideline of choice in research projects conducted in the field of Health Sciences' Studies. ${ }^{[10,11]}$ As a criterion of objectivity, patients were asked to portray in their drawings only the mouth/smile and no other parts of the face, thus centering the object of empirical analysis on the smile..$^{[1,12]}$

To proceed to the statistical analysis of the obtained data, the theoretical assumption of Sawyer et al. ${ }^{[14]}$ as well that of Pikunas ${ }^{[15]}$ was followed, and the sample was divided into four childhood and adolescence age groups: (i) "children" (8-12 years); (ii) "preteens" (13-14 years); (iii) "adolescents" (15-17 years), and (iv) "emerging adults" (18-24 years).

The statistic treatment of the descriptive data was analyzed using the software SPSS-Statistical Package for the Social Sciences IBM SPSS Statistics, version 23 for Windows, Lisbon, Portugal.

\section{RESULTS}

To understand the effect of the orthodontic appliance in the mental representation of the self-image of the individual-particularly that of the mouth/smile - the self-portraits drawn regarding M1 and M2 were tested empirically by comparison, by analyzing patients' mouth/smile, before and after the placement of the orthodontic appliance [Figure 1].

According to Table 1, three features are noticeable when comparing M1 and M2, evidencing alterations in the mental representation of the mouth/smile, before and after the placement of the orthodontic appliance: (i) crowded teeth, evident at the placement of the orthodontic appliance and virtually nonexistent design after its use; (ii) crooked teeth, idem (M1) and; (iii) misplaced teeth, ibidem. Regarding the pictorial representation of the category with diastema, different scores were obtained in M1 and M2 in all age groups apart from the emerging adults, where no significant differences were identified. Dental spacing also clearly decreased in all age groups from M1 to M2.

According to the statistical analysis performed [Table 2], a normal distribution was found in all age groups according to gender, which seems to be in line with the findings of Rodrigues et al. ${ }^{[16]}$

Regarding the written answer to the question: "Why do you use an orthodontic appliance?, the most important response amongst all age groups was the correction of crooked teeth $(68.7 \%)$, followed by the correction of interdental spaces $(12.7 \%)$ and malocclusion $(12.7 \%)$. Reasons such as to

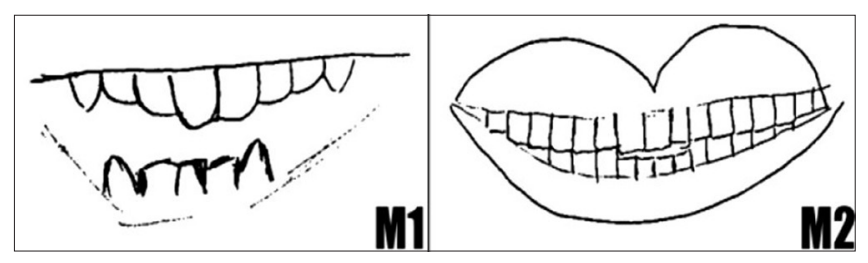

Figure 1: Self-portraits drawn before (M1) and after (M2) the placement of an orthodontic appliance 
Dias, et al.: Orhthodontic smile: A new categorization of the perfect smile

Table 1: Frequency of the subcategories found in participants' drawings before (M1) and after (M2) use of an orthodontic appliance (\%)

\begin{tabular}{|c|c|c|c|c|c|c|c|c|}
\hline & \multicolumn{2}{|c|}{ Children } & \multicolumn{2}{|c|}{ Preteens } & \multicolumn{2}{|c|}{ Adolescents } & \multicolumn{2}{|c|}{ Emerging adults } \\
\hline & M1 & M2 & M1 & M2 & M1 & M2 & M1 & M2 \\
\hline Absence of teeth & 0 & 0 & 0 & 0 & 0 & 2.3 & 8.6 & 14.3 \\
\hline Teethwithout details & 57.9 & 60.5 & 72.7 & 84.8 & 43.2 & 61.4 & 60 & 54.3 \\
\hline Fractured teeth & 7.9 & 0 & 6.1 & 0 & 0 & 2.3 & 8.6 & 0 \\
\hline Teeth with diastema & 10.5 & 0 & 24.2 & 6.1 & 27.3 & 0 & 8.6 & 0 \\
\hline Crowded teeth & 55.3 & 2.6 & 45.5 & 0 & 40.9 & 6.8 & 40 & 0 \\
\hline Crooked teeth & 89.5 & 21.1 & 84.8 & 9.1 & 88.6 & 20.5 & 88.6 & 20 \\
\hline In saw teeth & 23.7 & 18.4 & 18.2 & 6.1 & 22.7 & 13.6 & 25.7 & 11.4 \\
\hline Misplaced teeth & 89.5 & 21.1 & 90.9 & 18.2 & 95.5 & 15.9 & 88.6 & 14.3 \\
\hline Teeth with spacing & 26.3 & 5.3 & 36.4 & 6.1 & 36.4 & 9.1 & 40 & 8.6 \\
\hline Gingivaldeformation & 2.6 & 0 & 6.1 & 0 & 4.5 & 2.3 & 2.9 & 0 \\
\hline
\end{tabular}

Table 2: Frequency according to gender in all age groups (\%)

\begin{tabular}{lccc}
\hline & $\begin{array}{c}\text { Male, } \\
\boldsymbol{n}(\mathbf{\%})\end{array}$ & $\begin{array}{c}\text { Female, } \\
\boldsymbol{n}(\mathbf{\%})\end{array}$ & $\begin{array}{c}\text { Total, } \\
\boldsymbol{n}(\mathbf{\%})\end{array}$ \\
\hline Children (8-12 years) & $22(29.3)$ & $16(21.3)$ & $38(25.3)$ \\
Preteens (13-14 years) & $12(16)$ & $21(28)$ & $33(22)$ \\
Adolescents (15-17 years) & $25(33.3)$ & $19(25.3)$ & $44(29.3)$ \\
Emerging adults (18-24 years) & $16(21.3)$ & $19(25.3)$ & $35(23.3)$ \\
Total sample (8-24 years) & $75(100)$ & $75(100)$ & $150(100)$ \\
\hline
\end{tabular}

improve breathing or enjoying braces were the least mentioned by participants $(0.7 \%)$ [Table 3$]$.

Overall, results point that the improvement of oral health is another justification for the use of the orthodontic appliance $(9.3 \%)$, surpassing aesthetic motivations such as to be good looking $(8.7 \%)$ or to have beautiful teeth $(7.3 \%)$.

Nevertheless, the study revealed certain particularities regarding age groups: To have the perfect smile emerged as a strong concern for preteens $(15.2 \%)$ and for emerging adults $(22.9 \%)$, but not so much for adolescents $(2.3 \%)$, who seem to be less driven by the perfect smile's aesthetic motivation. As for categories related to the improvement of physical problems, such as muscle pain, only emerging adults have mentioned it as a motivation, due to discomfort (5.7\%).

Results also suggest that the main reasons for the use of the orthodontic appliance in the children age group are related to the correction of crooked teeth $(73.7 \%)$, bad occlusion (15, $8 \%)$, interdental spaces $(15.8 \%)$ and to have beautiful teeth $(15.8 \%)$. Reasons such as improved self-esteem, well-being, muscle pain, or enjoying braces were not mentioned in this age group. In the preteens age group, the main reason for the use of orthodontic appliance also seems to be related to the correction of crooked teeth $(63.6 \%)$, followed by interdental spaces $(18.2 \%)$, to have the perfect smile (6.1\%), and to be good looking (12.1\%). The categories of improvement of self-esteem, muscle pain, improvement of breathing, or enjoying braces were not mentioned in this age group either. Again, in the adolescent's age group, the correction of crooked teeth is the category most referred to as the major reason for orthodontic treatment $(79.5 \%)$, followed by the bad occlusion $(9.1 \%)$ and oral health $(9.1 \%)$. Adolescents do to not mention the categories of beautiful teeth, muscle pain, improvement of breathing, or enjoying braces as relevant. Finally, the emerging adult age group also mentions the crooked teeth correction as the main motivation for orthodontic treatment $(54.3 \%)$, followed by to have the perfect smile $(22.9 \%)$, bad occlusion $(17,1 \%)$ and to be good-looking (17.1\%). The categories of improved breathing and well-being were not referred to in this age group.

\section{Discussion}

In the present study, we found that despite gender having no influence on results, age seems to be a preponderant factor affecting subjects' esthetics perception of the smile, which seems to be in accordance with the perspective of several authors. ${ }^{[17-21]}$

Results obtained about the mental representation of the mouth/ smile of participants before (M1) and after (M2) the use of orthodontic appliance points to the correction of crooked teeth, diastemas, and fractures as main reasons for orthodontic treatment.

Drawings show that in M1, the smile was represented with longer anterior incisor teeth, creating a slightly descending line in the center and rising in the corners; while in M2, all teeth were represented with the same vertical dimension, with a straight upper incisal edge [Figure 1]. These parameters confirm those described by Goldstein ${ }^{[10]}$ for the older-appearing smile and the younger-appearing smile, respectively, thus differentiating smile according to age. In the present study, the smile evolves from an older-appearing smile in M1 to a younger-appearing smile in $\mathrm{M} 2$ after treatment [Figure 2].

The presence of diastemas in drawings can be observed in M1 [Figure 3] but not in M2 in all age groups, as evidenced in Table 1. Pre-teens are an exception to this rule. In this line of thought, Rodrigues et al. ${ }^{[16]}$ suggested that for adolescents 
Dias, et al.: Orhthodontic smile: A new categorization of the perfect smile

\begin{tabular}{|c|c|c|c|c|c|}
\hline & Children & Preteens & Adolescents & Emerging adults & Total (\%) \\
\hline Correction of crooked teeth & 73.7 & 63.6 & 79.5 & 54.3 & 68.7 \\
\hline Interdental spaces & 15.8 & 18.2 & 4.5 & 14.3 & 12.7 \\
\hline Correction of malocclusion & 15.8 & 9.1 & 9.1 & 17.1 & 12.7 \\
\hline To have the perfect smile & 5.3 & 15.2 & 2.3 & 22.9 & 10.7 \\
\hline Oral health & 13.2 & 3 & 9.1 & 11.4 & 9.3 \\
\hline To be good looking & 2.6 & 12.1 & 4.5 & 17.1 & 8.7 \\
\hline Beautiful teeth & 15.8 & 6.1 & 0 & 8.6 & 7.3 \\
\hline Well-being & 0 & 3 & 4.5 & 0 & 2 \\
\hline Improve self-esteem & 0 & 0 & 2.3 & 2.9 & 1.3 \\
\hline Muscle pain & 0 & 0 & 0 & 5.7 & 1.3 \\
\hline Improve breathing & 2.6 & 0 & 0 & 0 & 0.7 \\
\hline Enjoying braces & 0 & 0 & 0 & 2.9 & 0.7 \\
\hline
\end{tabular}

and adults, the presence of diastemas contaminated the esthetic appearance, negatively influencing the genesis of the smile. Contrary, Almeida et al. ${ }^{[22]}$ consider that in childhood, diastemas are not socially censored and considered as a derogatory factor but have a natural connotation, are present in deciduous teeth, and disappear naturally or by means of a simple intervention. Nevertheless, and paradoxically, in the present study, children always represent pictorially the mouth/ smile in M2 without the presence of diastemas [Figure 3], which is in line with the findings of Almeida et al. ${ }^{[22]}$

Furthermore, the representation of the smile arc in M2 as described by Sarver ${ }^{[4]}$ seems to be the equivalent of the superior smile as defined by Freitas-Magalhães. ${ }^{[3]}$

The fractures of dental parts in drawings [Figure 4] are present in most age groups in M1, with emerging adults as the most prominent group in this subcategory $(8.6 \%)$.

In general, the main motivational factors that determine the functional use of an orthodontic appliance are defined by the crooked teeth correction, malocclusion correction, and interdental spaces categories.

The literature review refers to the severity of malocclusion as the main determinant psychosocial factor underpinning the use of an orthodontic appliance, followed by the aesthetics of the smile and the subject's self-esteem. According to these authors, ${ }^{[19-21,23]}$ malocclusions seem to have a greater psychosocial impact than other parameters, denoting that subjects seem to be concerned about the placement of teeth in the dental arch rather than in the esthetic details of their smile. ${ }^{[24]}$

In the present study, we have found that the correction of crooked teeth is the main reason for children and pre-teens to undergo orthodontic treatment. In addition, the dissatisfaction with the dental appearance in children and adolescents is related to missing teeth and to a greater anterior irregularity of the upper jaw. The study also found that in the adolescent's age group, none of the subjects referred to the importance of having beautiful teeth as a reason for the use of an orthodontic appliance. However, these results seem to be opposed to those

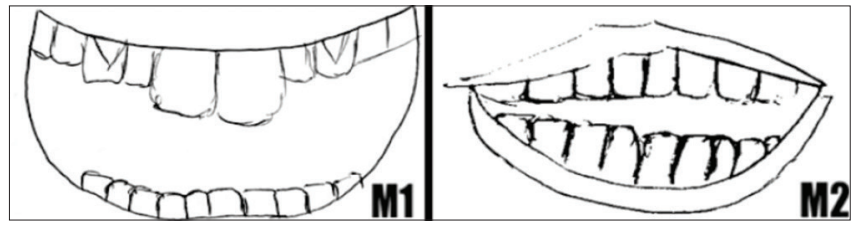

Figure 2: Younger-appearing smiles (M1) and older-appearing smile (M2)
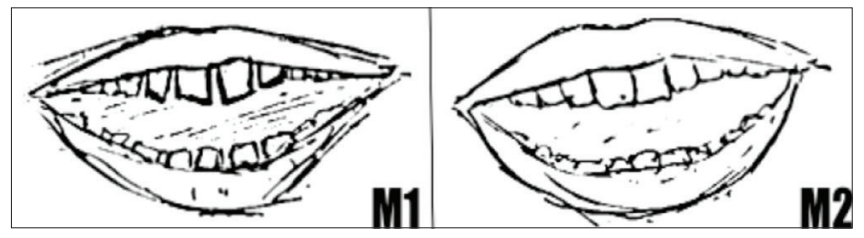

Figure 3: Presence of diastema in M1 and absence of diastema in M2

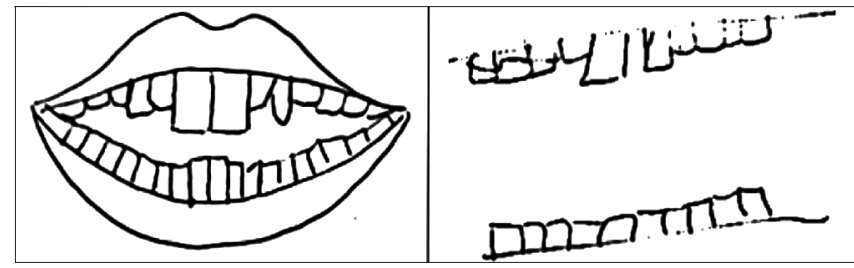

Figure 4: The fractures of dental parts, mostly drawn in M1

obtained by Bica et al., ${ }^{[25]}$ where most patients pointed to the improvement of the appearance of the face as a motivation for orthodontic treatment. Similar results were described by Elias et al. ${ }^{[26]}$ noting that according to the particularities of the age group studied, oral health and esthetics played a preponderant role regarding the self-image of the face. Following this line of thought, our results confirm that both esthetical and oral health motivations play a role in orthodontic treatment in emerging adults, in addition to structural and functional reasons. Emerging adults mentioned by order of relevance, the correction of crooked teeth, to have the perfect smile, correction of malocclusion and of to be good looking as factors for orthodontic treatment, discarding well-being and the improvement of breathing as categorical determinants. These findings are in line with those of Delalíbera et al., ${ }^{[27]}$ which related orthodontic treatment with emerging adults' personal 
Dias, et al.: Orhthodontic smile: A new categorization of the perfect smile

relationships, leading to the conclusion that the perception of dentofacial deformities could affect the adaptation of individuals to society. In accordance, adolescents $(2.3 \%)$ and emerging adults $(2.9 \%)$ refer the improvement of self-esteem as the leitmotif for the use of an orthodontic appliance, which may signal concern regarding the link of self-esteem to the appearance of the oral cavity, such as described by Basha et al. ${ }^{[28]}$

Overall, the correction of crooked teeth was the most cited reason in all age groups to undergo orthodontic treatment. Thus, our results suggest the attainable of the perfect smile in an esthetics point of view was least a determinant for the use of an orthodontic appliance than the good functioning of the oral cavity. The orthodontic smile-seen here as a healthy, well-functioning smile, was more important than the esthetic perfect smile for all participants, particularly to adolescents. Hence, we propose the orthodontic smile as a new classification for the smile in the orthodontic setting, that has into consideration the social healthy display of perfect teeth.

\section{Conclusions}

Smile esthetics has become the main object of current orthodontic practice, in which malocclusion is one of the three major oral disorders that may imply oral functional problems, which, in turn, may imply aesthetic impact.

According to the results obtained in the present study, the main reason that leads participants to orthodontic treatment is related to functional questions. The maximization of the mental representation of the orthodontic smile emerged here as a new smile category associated with a healthy, well-functioning smile with perfect teeth, in clear contradiction to the esthetic perfect smile.

\section{Financial support and sponsorship}

Nil.

\section{Conflicts of interest}

There are no conflicts of interest.

\section{REFERENCES}

1. Do Rosário Dias M, Naben L, Monteiro A, Ferreira A, Alves V, Delgado A. When the silence speaks: The smile. J Biosci Med 2018;6:13-20

2. Sarver DM, Ackerman MB. Dynamic smile visualization and quantification: Part 1. Evolution of the concept and dynamic records for smile capture. Am J Orthod Dentofacial Orthop 2003;124:4-12.

3. Freitas-Magalhães A. A Psicologia do Sorriso Humano. Portugal: Edições Universidade Fernando Pessoa; 2009.

4. Sarver DM. The importance of incisor positioning in the esthetic smile: The smile arc. Am J Orthod Dentofacial Orthop 2001;120:98-111.

5. Sabri R. Orthodontic objectives in orthognathic surgery: State of the art today. World J Orthod 2006; 7:177-91.

6. Tjan AH, Miller GD, The JG. Some esthetic factors in a smile. J Prosthet Dent 1984;51:24-8.

7. Mabrito C. Elements of a beautiful smile. N M Dent J 1996;47:20-1.

8. Frush JO, Fisher RD. The dysesthetic interpretation of the dentogenic concept. J Prosthet Dentistry 1958;8:558-81.

9. Miller CJ. The smile line as a guide to anterior esthetics. Dent Clin North Am 1989;33:157-64.

10. Goldstein RE. Change Your Smile. Discover how a New Smile Can Transform your Life. Chicago: Quintessence Publishing; 1997. 2009.

11. Janson G, Branco NC, Morais JF, Freitas MR. Smile attractiveness in patients with Class II division 1 subdivision malocclusions treated with different tooth extraction protocols. Eur J Orthod 2014;36:1-8.

12. Machado AW. 10 commandments of smile esthetics. Dental Press J Orthod 2014;19:136-57.

13. Cotrim ER, Vasconcelos Júnior ÁV, Haddad AC, Reis SA. Perception of adults' smile esthetics among orthodontists, clinicians and laypeople. Dental Press J Orthod 2015;20:40-4.

14. Sawyer MD, Susan M, Azzopardi P, Wickremarathne MD, Patton MD. The age of adolescence. Lancet Criança Saúde Adolesc 2018;2:223-8.

15. Pikunas J. Desenvolvimento Humano. Uma Ciência Emergente. São Paulo: McGraw-Hill; 1979.

16. Rodrigues Cde D, Magnani R, Machado MS, Oliveira OB. The perception of smile attractiveness. Angle Orthod 2009;79:634-9.

17. Tüzgiray YB, Kaya B. Factors affecting smile esthetics. Turk J Orthod 2013;26:58-64.

18. Mokhtar HA, Abuljadayel LW, Al-Ali RM, Yousef M. The perception of smile attractiveness among Saudi population. Clin Cosmet Investig Dent 2015;7:17-23.

19. Pithon MM, Bastos GW, Miranda NS, Sampaio T, Ribeiro TP, Nascimento LE, et al. Esthetic perception of black spaces between maxillary central incisors by different age groups. Am J Orthod Dentofac Orthop 2013;143:371-5.

20. Lacerda-Santos R, Pereira TB, Pithon MM. Esthetic perception of the buccal corridor in different facial types by laypersons of different ages. Biosci J 2015;31:1283-90.

21. Gerritsen AE, Sarita P, Witter DJ, Kreulen CM, Mulder J, Creugers NH. Esthetic perception of missing teeth among a group of Tanzanian adults. Int J Prosthodont 2008;21:169-73.

22. Almeida A, Leite I, Melgaço C, Marques L. Dissatisfaction with dentofacial appearence and the normative need for orthodontic treatment: Determinants Factors. Dent Press J Orthod 2014;19:120-6.

23. Lukez A, Pavlic A, Trinajstic Zrinski M, Spalj S. The unique contribution of elements of smile aesthetics to psychosocial well-being. J Oral Rehabil 2015;42:275-81.

24. Peres KG, Traebert ESA, Marcenes W. Differences between selfperception and normative criteria in the identification of malocclusions. Rev Saude Publica 2002;36:230-6.

25. Bica I, Cunha M, Costa J, Rodrigues V, Neves D, Albuquerque I, et al. Body perception and satisfaction in adolescents and the relationship to their oral health. Millenium 2011;40:115-31.

26. Elias MS, Cano MA, Junior W, Ferriani M. The importance of oral health for adolescents from different social strata in the city of Ribeirão Preto. Rev Lat Am Enfermagem 2001;9:88-95.

27. Delalíbera H, Da Silva M, Pascotto R, Terada H, Terada R. Aesthetic evaluation of patients undergoing orthodontic treatment. Acta Scientiarum Health Sci Maringá 2010;32:93-100.

28. Basha S, Mohamed RN, Swamy HS, Parameshwarappa P. Untreated gross dental malocclusion in adolescents: Psychological impact and effect on academic performance in school. Oral Health Prev Dent 2016;14:63-9. 